\title{
Impact of regional policy on evolution of innovation clusters in Asia-Pacific region
}

\author{
Trifonova Natalia Victorovna \\ International Business Department \\ Saint-Petersburg State University of Economics \\ Saint-Petersburg, Russian Federation \\ nvtrifon@mail.ru
}

Vardanyan Irina Samvelovna

International Business Department

Saint-Petersburg State University of Economics

Saint-Petersburg, Russian Federation

ilona251@yandex.ru

\author{
Klementovichus Yana Yazepovna \\ Higher Economic School \\ Saint-Petersburg State University of Economics \\ Saint-Petersburg, Russian Federation \\ dir@hes.spb.ru \\ Proshkina Aleksandra Sergeevna \\ International Business Department \\ Saint-Petersburg State University of Economics \\ Saint-Petersburg, Russian Federation \\ alexproshkina@mail.ru
}

\author{
Melnikova Anastasia Aleksandrovna \\ International Business Department \\ Saint-Petersburg State University of Economics \\ Saint-Petersburg, Russian Federation \\ aa_melnikova@bk.ru
}

\begin{abstract}
This article develops the crucial points of Sapience Integra model concerning the dynamics of intelligence core of the innovation cluster, determining the enlarged division of innovation clusters into technological and researchentrepreneurial types. The authors define the intelligence core as a structurally stable component. There is a new approach to define the innovation cluster as a type of territorial concentration including the interpenetration and mutual influence of the research potential, the dominance of the university's research sector, the entrepreneurship and the intellectual results within the main cluster structural components. Thus, the innovative cluster is considered as the most mobile and evolutionarily predictable variant of the integrated structure and territorial concentration. The model presents the perspective of innovation policy within Asia-Pacific region.
\end{abstract}

Keywords - Cluster approach, innovation cluster, intelligence core, developing markets, sustainability

I.

INTRODUCTION

Over the past two decades, clusters, as a form of territorial concentration and agglomeration of research and entrepreneurial activities, also have been recognized as innovation centers. Moreover, the meaning of innovation clusters is assumed in national and global scale. Some clusters can be defined as innovative clusters because its sustainability and effectiveness is determined by the complementarity of assets, resources and competences. The changing role of the educational and research component in the intelligence core within the cluster is also observed [1]. In the model of innovation cluster "Sapience Integra" proposed by the authors, the main dynamic processes in the core are determined by the influence of regional or national innovation policies. At the same time, the ratio of regional and national innovation policies depends on the characteristics of the region, the homogeneous or heterogeneous nature of the innovation policy being implemented.

In the framework of the Sapience Integra model, the authors consider the region as a complex regional site. Inside this object the institutional and economic changes occur in accordance with the industry direction, selected time horizon, and state innovation programs.

Q1: What determines the evolutionary dynamics of an innovation cluster?

Q2: If the intelligence core is dynamics, what changes may occur within?

Q3: How do the regional patterns affect the evolutionary dynamics in the innovation cluster?

The purpose of the paper is to determine the impact of innovation programs on the development of territorial concentration in the Asia-Pacific Zone based on the Sapience Integra model.

The subject of the analytical review was regional and country innovative programs in various areas of the AsiaPacific region as a significant influential element that ensures the dynamics of innovative clusters of the region.

The theoretical framework of the research defines a logical structural model describing the cluster as the interaction of state institutions, business and educational structures. Within this approach, the universities are defined like both research centers and business institutions influencing the economy on a global scale. In terms of Sapience Integra model, the authors introduce the following definitions. 
Innovative cluster means a fundamentally new type of territorial concentration with an interpenetration of research potential and entrepreneurial activity of university and business community.

Intelligence core is defined as a cumulative intellectual outcome from the functioning of the innovation cluster.

Technologies are described as algorithmized outcome of intellectual activity of structural elements within the innovation cluster.

Skills and competences are described as the outcome of intellectual activity of structural elements within the innovation cluster reproduced in action.

Knowledge is assumed as the outcome of intellectual activity that can be broadcasted over the environment of the innovation cluster.

\section{II. \\ SAPIENCE INTEGRA MODEL OF INNTELLIGENCE CORE IN INNOVATION CLUSTER}

In the structure of innovative clusters, the different actors such as business structures, research centers, academic institutes and patent offices are in focus today. The model of the intelligence core Sapience Integra (Fig. 1) is based on the assumption that the system-forming element of the innovation cluster is the cumulative intellectual outcome from the functioning. The intellectual result is heterogeneous, fundamentally and evolutionarily changeable. In the evolutionary sequence, the following components are defined:

- technologies (the first evolutionary stage);

- skills and competencies (the second evolutionary stage);

- knowledge (the third evolutionary stage).

Considering the intelligence core of the innovation cluster is in dynamic, the evolution of the cluster itself is assumed depending on the dominance of technology, skills or knowledge. So in the period of the technological dominance (1) in the core, the innovation cluster can be classified as a technological type, which is confirmed by the largest representation in its structure of business structures. In the period when skills and organizational competencies are in prevalence within the intellectual outcome, the cluster passes through the intermediate stage (2). It is subsequently replaced by the transformation period of dominance of knowledge relevant for the industry and region (3). This type of innovation cluster is defined as research-entrepreneurial.

The dynamics of the intelligence core specified in the logical structure model is determined by the dynamics and effectiveness of regional policy as well as by the activity of state institutions, represented in the zone of the innovation cluster location. The activity of state institutions is the result of innovation policy implementation.

The proposed approach to identification of the intelligence core within the innovation enables one to highlight the changes in the composition of the cluster and the transition of the dominant company from the production and business structure to major university and research centers within and in connection with the dynamic processes in the intelligence.
Also it gives a clear view on two main types of innovation clusters (technological and research-entrepreneurial) with a description of the transition form. The Sapience Integra model develops the basic assumptions of the "Triple Helix" concept. First of all, it focuses on specifying the factors provided the dynamics of the sustainability within the innovation cluster. However, there are still the key points of the Triple Helix concept:

- advancement of the third active participant in the innovation cluster - educational structure (university);

- generation and transmission of socially organized knowledge;

- interaction of the participants in the cluster goes from the binary coordinate system to the ternary system;

- the existence of synergies between the three spheres: intellectual, business and government.

The evolution of the intelligence core is supposed to lay on the synergy of the three spheres: science, business and state. A cluster formation depends on regional differences in a way of the state programs dynamics or institutional and infrastructural support for cluster development. In the US and Canada University of Utah (UU), Ryerson Digital Media Zone, MIT had emerged upon the influence of socio-economic factors (both science and business spheres as a catalyst for the processes of territorial concentration). In Europe, the appearance of clusters is taking place with active participation of the state, implementing a special policy in this area (the government sphere as a catalyst for the processes of territorial concentration). In the innovation-leading countries from the Asia-Pacific Zone, it was the initiative of the governmental and business spheres to form innovation clusters. After a while, such clusters became attractive integrated structures for the research and academic community. That is why, the clusters of the Asia-Pacific Zone seems to be the most interesting for this analytical review. Regional cluster policy is supported and regulated by several directions of the state economic policy: regional, innovative, industrial (sectoral) [2]. In addition, the influence of policies in education, entrepreneurship and other spheres is also being considered.

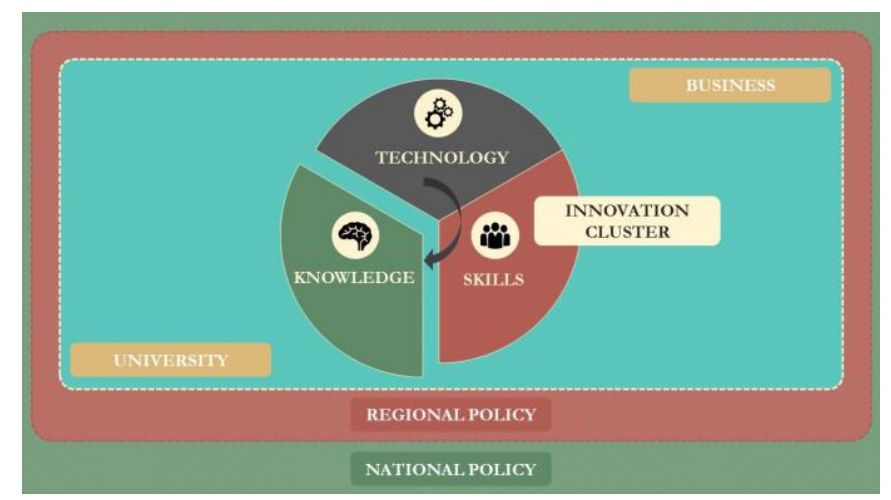

Fig.1. "Sapience Integra" model of innovation cluster. Authors: Trifonova N., Epstein M., Borovskaya I., Vardanyan I., Melnikova A., Proshkina A. (SaintPetersburg State University of Economics) 
Taking into account the importance and effectiveness of clustering as a factor of sustainable competitiveness and economic development of regions, the role of clustering policy is increasing. Initially it was developed in the early 1990s; later such policies became widely spread in developed countries, rather than in developing countries and countries with economies in transition [3]. It is worth emphasizing that a clustering policy is more focused on stimulating cluster initiatives. Practice had shown that the highest level of regional competitiveness is achieved while innovation clusters are actively developed. Clustering itself does not guarantee a high level of innovation: its advantages are reflected only in those clusters where there is already a large representation of innovation firms and a large amount of knowledge accumulated [4]. So the research-entrepreneurial clusters with a relatively large potential for innovation shape for generating the opportunities and implementation of initiatives. This type of cluster is a dynamic self-developing system, based on the use of the synergy effect

In the Sapience Integra model, the regional and national policies are presented without specification of the innovative character of the national policy. The model does not specify the scope of the region, its territorial significance, institutional, program-innovation and economic homogeneity or heterogeneity. That is why, concerning the Asia-Pacific Zone, the following approach is defined:

- to define the institutional and economic environment of the region as heterogeneous;

- to identify the regional types accompanied by the homogenization of national innovation programs and policies;

- to consider the region as an enlarged territorial-country agglomeration.

This view is in line with the current European policy, supporting national and regional efforts to develop clusters through specially created organizations (European Cluster Observatory, Europe INNOVA initiative, European Cluster Alliance) that implement both analytical and facilitation functions, promoting cooperation between regions. Cluster's cooperation ensures the formation of new scientific and business contacts, training, adaptation of best practices for managing the clusters themselves. Cluster's cooperation also increases mobility of students, scientists, entrepreneurs, expatriates. So it strengthens the international orientation of regional and national clusters. Therefore, the harmonization of innovation policies, which implies a synergistic effect from the activity of innovation clusters in the Asia-Pacific Zone, seems to be a logical step in the development.

\section{HETEROGENEOUS INSTITUTIONAL AND ECONOMIC ENVIRONMENT IN ASIA-PACIFIC ZONE}

Industrial countries in the Asia-Pacific Zone are presented by a group of countries that started the process of modernization in the second half of the twentieth century. This group includes a number of East Asian countries ("Asian tigers"): South Korea, Taiwan, Hong Kong, Singapore (the "first wave"), as well as the Philippines, Thailand, Malaysia ("second wave") and Vietnam ("third wave"). The development of these countries follows a scenario similar to the Japanese economy developed earlier [5]. It started with the agrarian economy and traditional low-tech, but labor-intensive industries. At the same time, the economy relied on local raw base. The second step was the government's implementation of a protectionist policy aimed at import substitution and massive investment in the leading industries. At the third stage, the economies of these countries were transformed into export-oriented, open to foreign investment with a developed high-tech sector, for example, electronics. Concerning the technologies, the national enterprises started with the copying of foreign models. Then the companies moved to the modification of foreign analogues and, finally, created own scientific and technical units capable to produce new advanced samples of technologically complex products. At the same time, there was a transition to increasingly complex production systems, which, for example, was reflected in the growth of industrial electronics in comparison with the domestic one in South Asian countries.

In the most dynamically developing countries, such as South Korea, Hong Kong or Singapore, there development of the service sector takes place faster. This sector begins to dominate in the structure of the economy. As a result, the structure of the economy of the newly industrialized Asian countries has been radically changed [6]. This applies to the territorial placement, the qualification of the workforce and the quality of the institutional environment. This can be recorded as the fourth stage of the evolution in the economies of these countries.

Institutional changes play a significant role in the evolution of the economy. So the initial impetus for accelerated industrialization in South Korea in the late 1940s was linked to agrarian reform. Overcoming the crisis phenomena in the 1990s was related to the political democratization and shifting the emphasis from state support for chaebols to providing equal favorable conditions for independent enterprises, including, small and medium business.

The most important factor that contributed to the structural reorganization of the economy under consideration is the improvement of the labor qualification. The initial advantage of these economies was the availability of cheap and numerous labor. Later these countries provided universal secondary education, raised the level of general and professional training to modern standards. The priority of education has become the basis of this "educational explosion" that has changed the quality of labor resources. Today these countries invest in the education system from 2.5 to $4.5 \%$ of GDP. Up to a third of all high school graduates continue their studies at universities. Most of them have the opportunity to study in the US and Western Europe. The majority of students studying abroad, for the most part, return back to country despite the fact that the level of compensation is lower than it is in western countries [7]. Local universities have also become an important part of the world higher education system.

The countries of the "first wave" in Asia send about 1-2\% of GDP to R\&D. By this indicator the countries are getting closer to the western countries. Upon the experience of 
western countries, the authorities of the newly industrialized countries went along the path of creating industrial and technological parks. By the end of the twentieth century, such centers already existed in most Asian new industrial countries.

A bright example of such center is the Hsinchu Science and Technology Industrial Park in Taiwan. The scientific core of the center consists of two universities. The production base consists of firms specializing in the production of high-tech products. In Singapore, the scientific base of a similar center consists of 10 state research institutes while the production base includes more than 40 industrial companies. In Malaysia, the leading research and industrial park is located on Penang island near the west coast of the country. This park is a major world center for the production of chips.

\section{IV.}

HOMOGENIZATION OF THE INNOVATION ENVIRONMENT IN ASIA-PACIFIC ZONE

Asia-Pacific Zone is distinguished due to its size, population, economic growth and innovation potential. The countries within Asia-Pacific Zone actively stimulate innovative development. Despite the heterogeneity and significant differences in the economic level, there is an opportunity to highlight a certain homogeneity in the implemented national innovation policy. So the countries could be grouped as follows.

\section{Innovation leadership group}

Innovative leadership in Asia-Pacific Zone traditionally belongs to Japan, which is identified with the notion of hi-tech industry. This result was achieved at the end of the 20th century through the interaction of all spheres in the innovation sector: research institutes, transnational corporations, governmental agencies, small and medium-sized businesses. According to The Global Innovation Index 2016, the country is among the top three world leaders in one of the main indicators of the rating - "Quality of Innovation". This indicator concerns the level of innovation development of national universities, the number of scientific publications and international patent applications. According to the World Intellectual Property Organization (WIPO) for the year 2015, 318,000 patent applications were registered in Japan. It provided the country to take the third place in the ranking of leaders according to World Intellectual Property Indicators 2016.

The Japanese system of innovation is significantly different from similar systems in western countries. So, almost all R\&D are performed in civilian use. It is about $80 \%$ of $\mathrm{R} \& \mathrm{D}$ expenditures are pertained on industry, in particular on medicine, information and computer systems, security systems, careful use of the environment, space industry, nanotechnology and robotics. Japan is a one of the leaders in the field of applied research and development.

On the territory of Japan, in addition to the world-famous Kobe Biomedical Innovation Cluster, there are two large research and entrepreneurial clusters: Northern Osaka Biomedical Cluster and Protein Mall Kansai. The participants in these clusters are not only well-known companies in the field of biomedicine, but also large educational institutions, including Kyoto University's Institute and Osaka Health Science university. The activities of clusters are accompanied by support of regional innovative programs implemented by local authorities.

\section{Innovation breakthrough group}

In the group of countries, which relied on the innovation policy in socio-economic transformations, there are South Korea, Singapore and Malaysia. So the focus on innovation policy enabled South Korea to overcome the gap with the world economic leaders in the shortest time. According to the World Bank, the country is investing in research and development significant funds in the amount of $4.29 \%$ of GDP. The chosen policy brings the results. So, in the Global Innovation Index 2016, South Korea took the 11th place. In the global innovation index of Bloomberg for 2016 and 2017, South Korea is recognized as the country with the most innovative economy in the world. Leadership of the country is provided by indicators in the field of international $R \& D$ relations, production with high added value and patent activity (213,000 registered patents for 2015), higher education level and research concentration. The country demonstrates high performance indicators for the implementation of new ideas and projects. Unlike the model when new ideas are transformed into start-ups, in South Korea it is encouraged the innovation generation within companies. It also contributes to the success in world markets. The innovation policy of South Korea received an impetus for development in the early 2000s. Now it yields tangible results.. In 2006, the Government of South Korea presented a program for the regional innovative development. The development of the research component within clusters through the revitalization of educational structures was the crucial part of the established program. Several large innovation clusters operate on the territory of this country, including Changwon Industrial Complex, Seoul Digital Industrial Complex, UIsan Automobile Cluster

Singapore pays high priority to the development of innovative infrastructure and support for entrepreneurship. In the ranking of The Global Innovation Index, Singapore ranked first in Asia and 6th in the world. Speaking about innovation system in Singapore, the state plays an active role in creating the system linking the university and business organizations. A key factor in the success of the state support for innovation in Singapore is the systematic nature of the measures being undertaken.

A distinctive feature of Singapore is the education and health system. In Singapore, more than $80 \%$ of the technology companies are included on the Fortune 1000 list. Singapore has made considerable progress in protecting investors' rights, protecting intellectual property. In the world competitiveness index, it ranks second in the world according to these indicators. Also the government supports the initiatives in IT and computering systems by participating in funds. Singapore is oriented to implementation of new technologies in different spheres of the economy, as well to being an initiator of its application in the state projects. For instance, in 2016 the state has announced a plan to use unmanned buses in the largest cities. Moreover, there is established Innovation Cluster Program. The aim of this program is to encourage technology organizations and economic agencies to work with industry to form innovation clusters. In order to help Singapore to achieve the status of as a world leader in advanced manufacturing, National Additive Manufacturing 
Innovation Cluster (NAMIC) was set. The cluster specializes in 3D printing and digital technologies.

Malaysia according to the Global Innovation Index also achieved high performance in the field of innovation policy taking a $35^{\text {th }}$ place in ranking. The dynamics of the Malaysian economy is based on long-term state policy, supporting a stable development of the agrarian sector and expecting growth in export-oriented industries. In recent decades, Malaysia has focused on the role of innovations in the economy. Malaysia increased its efforts to strengthen the national innovation system by developing a national model "Vision 2020". The model was designed to transform Malaysia's economy with a priority on innovations. This model asserts the importance of science and education with the pursuit of knowledge in the production sphere, ranging from biotechnology and information technology to agriculture. A crucial component is a Multimedia Super Corridor MSC Malaysia.

"Multimedia Super Corridor MSC Malaysia" is an innovative project in the field of information and multimedia technologies, implemented in Malaysia to ensure the transition from a traditional economy to an economy based on advanced informational technologies. The core project includes the "cities of the future" Cyberjaya and Putrajaya. Cyberjaya is a science technology park primarily focused on information technology - Silicon Valley of Malaysia. Putrajaya is being transformed into the new administrative capital of the country.

Concerning this group of countries, it is seems to consider Thailnd as a potential member within this classification. Currently Thailand's economy is characterized by active investment and innovations, also as a significant increase in the use of advanced scientific and hi-tech achievements. The national government is focused on 2 crucial points namely commitment to the principles of free-market and export orientation.

According to government experts, in order to increase the competitiveness of Thai products in the global market, the use of innovative technologies should be facilitated. Thus, implies a set of institutions for promoting the innovations. National Innovation Agency of Thailand (NIAT) was established by the Ministry of Science and Technology in October 2003. The Agency concentrates on the development of innovations in the various sectors that ultimately leads to increased productivity, enhanced competitiveness of Thai products in the world market, and the further development of social sphere.

\section{Innovation layer group}

In the modern model of development and the formation of economic development in China and India, innovative achievements play an important role.

According to The Global Innovation Index 2016, India remains the leader among the countries of Central and South Asia, ranking first in the region, and 66th in the overall rating. India demonstrates high rates of innovation quality (quality of scientific publications, patents, university ratings). It also promotes the commercialization of scientific developments, in order to increase the high-tech component in the structure of the economy. This is facilitated by the Scientific and Industrial Research Council (CSIR). It includes 39 laboratories. CSIR is the largest center of $R \& D$ in India. Concerning the characteristic of the Indian innovation system, the government supports small and medium-sized businesses in the development of associations in the form of clusters with large enterprises, guaranteeing intellectual property rights, providing access to infrastructure.

China, according to The Global Innovation Index 2016, takes the 25th position. The country takes the status of a developing innovative power, despite patent leadership. Many of the technologies used are borrowed, since China actively imports it and forms R\&D base on the results of innovation imports. However, the policy of the state today in this area is aimed at encouraging its own innovations. In China, there are several national and regional programs being implemented to support scientific research and commercialize R\&D. It is noteworthy that the scientific publications and developments fall to the share of universities. The state allocates about $2 \%$ of GDP for these purposes.

So, in 1988, the State Council of China approved the project to create the Beijing Industrial Development Zone, on the basis of which appeared Zhongguancun Science Park. Now this park takes the status of "Chinese Silicon Valley." This innovation cluster for the past two decades has brought together more than 20,000 participants, including world leaders in the hi-tech industry, such as Lenovo and Baidu. Initially, electronics and information technology were the core branches of development. Recently, the range of industries in the cluster has included biomedicine, energy sector, aerospace industry. Zhongguancun Science Park paid considerable attention to cooperation with other innovation clusters. Zhongguancun has 10 foreign offices: in Silicon Valley, Washington, Tokyo, Toronto and London.

Another priority project in the framework of the developing innovation clusters in China was Suzhou Industrial Park. This project was a bright example of a successful strategic partnership between the two states - China and Singapore. Cluster members present their developments in various sectors, including nanotechnology, software, automotive industry and medicine. By the end of October 2015 , this cluster has attracted more than 5,000 foreign enterprises to cooperate, and the volume of aggregate foreign investment amounted to more than 37 billion euros.

\section{CONCLUSION}

Scientific research and methodological recommendations, developed by consultant practitioners on the formation of a regional cluster policy, emphasize the need to take into account the specifics of the region and the cluster itself. The cluster's strengths and weaknesses, the stage of development, the market position in the development of effective policy should be considered. However, there is an attempt to establish classification of the countries in Asia-Pacific Zone upon their approach to clustering policy. Besides, the need to coordinate cluster policy with other directions of economic policy, which also influences the activity of the cluster, remains urgent. In this case, the specificity of the cluster will affect the corresponding policies at the regional and national level. 


\section{Acknowledgment}

The authors would like to thank their colleagues Borovskaya I., Shevtsova O. and Epstein M. for their support and assistance with this project. This work was supported by St. Petersburg State University of Economics (St. Petersburg State University of Economics Academic Council Statement No. 12 on October 28, 2016; Academic Council Statement No.3 on March 10, 2017).

\section{References}

[1] Wang, J., Shapira P. Partnering with Universities: A Good Choice for Nanotechnology Start-up Firms. Small Business Economics, vol. 38, Iss., 2012.

[2] OECD Reviews of Regional Innovation: Competitive Regional Clusters: National Policy Approaches. OECD, 2007.

[3] Ketels C., Lindqvist G., Sölvell Ö. Cluster Initiatives in Developing and Transition Economies. Center for Strategy and Competitiveness: Stockholm, 2006.

[4] Beaudry C., Breschi S. Are firms in clusters really more innovative? Economics of Innovation and New Technology, 12 (4), pp. 325-340, 2003.

[5] IMF Study. Asia and Pacific Stabilizing and Outperforming Other Regions. Regional economic outlook. Asia and Pacific. Washington, D.C., 2015.

[6] Pongsaparn, R., Unteroberdoerster, O. Financial Integration and Rebalancing in Asia. Working Paper 11/243, International Monetary Fund, Washington, 2011.

[7] Williams, L., Woodson, T. The Future of Innovation Studies in Less Economically Developed Countries .Minerva: A Review of Science, Learning \& Policy, vol. 50(2), pp. 221-237, 2012.

[8] Etzkowitz H., Leydesdorff L. The Triple Helix - University - Industry Government Relations: A Laboratory for Knowledge - Based Economic Development. EASST Review 14, 1995.
[9] IMF Study. Asia and Pacific Stabilizing and Outperforming Other Regions. Regional economic outlook. Asia and Pacific. - Washington, D.C., 2015.

[10]Li B.Z., Luo X.F., Zhang, Y. Study on Knowledge Production Mechanism of Enterprise Original Innovation with Industry-UniversityResearch Cooperative Mode- The Empirical Study Based on Enterprises in High-Tech Fields. Management Review, vol. 7, pp. 82-91, 2014.

[11]Park, S.C. Strategy for Innovative Clusters in Changwon Industrial Complex. South Korea, Korea Observer, vol. 38, no.4, pp. 523-554, 2007.

[12]Ranga M., Hoareau C., Durrazzi N., Etzkowitz H., Marcucci P., Usher A. Study on University-Business Cooperation in the US: final report, May 2013. - London School of Economics and Political Science, p. 143.

[13] Shinn T. The Triple Helix and New Production of Knowledge: Prepackaged Thinking on Science and Technology. Social Studies of Science, vol. 32(4), pp. 599-614, 2002.

[14]World Economic Forum. The Shifting Geography of Global Value Chains: Implications for Developing Countries and Trade Policy. Geneva: World Economic Forum, 2012.

[15] Wu J.X. A Comprehensive Framework to Understand Innovation Culture and Its Policy. China Soft Science, vol. 5, no. 65, 2011.

[16] Aharonson B. S., Baum J. A. C. \& Feldman M. P. Desperately seeking spillovers? Increasing returns, industrial organization and the location of new entrants in geographic and technological space. Industrial and Corporate Change, vol. 16(1), pp. 89-130, 2007.

[17]Kwon S. J., Park E. \& Kim K. J. What drives successful social networking services? A comparative analysis of user acceptance of facebook and twitter. The Social Science Journal, vol. 51, pp. 534-544. , 2014

[18]Lee S. \& Lee K. A comparative study of innovative cluster on gumi and Changwon national industrial complexes. Journal of the Korean Regional Development Association, vol.20, pp. 1-27, 2008.

[19]Wennberg K. and Lindqvist G. How the entrepreneurs in cluster contribute to economic growth, SSE7EFI Working Paper Series in Business Administration no.3, 2008.

[20] Klepper S. The origin and growth of industry clusters: The making of silicon valley and detroit. Journal of Urban Economics, no. 67, pp. 15-32, 2010. 